\title{
Is Counterpulsation a Potential Therapy for Ischemic Stroke?
}

\author{
Jing Hao Han ${ }^{\mathrm{a}, \mathrm{b}}$ Ka Sing Wong ${ }^{\mathrm{a}}$ \\ ${ }^{a}$ Department of Medicine and Therapeutics, Chinese University of Hong Kong, Hong Kong, and ${ }^{b}$ Department of \\ Neurology, Huashan Hospital, Fudan University, Shanghai, China
}

\section{Key Words}

Ischemic stroke $\cdot$ Cerebral blood flow $\cdot$ Counterpulsation

\begin{abstract}
Background: Despite the rapid progress in stroke prevention, effective acute stroke treatment except for thrombolysis is still lacking. Hypoperfusion is related to unfavorable functional outcome, further strokes and long-term mortality. Therefore, the need for a safe and effective way of increasing the cerebral blood flow seems obvious. Currently, there is a growing body of evidence to suggest that external counterpulsation (ECP) may enhance the blood supply to the brain and thus may be beneficial to patients with ischemic stroke. Methods: A MEDLINE search in combination with a search for papers in Chinese literature in the Wan Fang and China Academic Journal databases was carried out. Results: Preliminary investigations suggested that ECP may improve the clinical outcome of stroke patients. However, well-designed clinical studies exploring the therapeutic effects of ECP in ischemic stroke are very limited. Conclusions: Randomized-controlled trials with a large sample size are needed to further define the efficacy and safety of ECP in acute stroke management. Future studies should provide insight into the value of ECP in ischemic stroke as well as its possible mechanisms.

Copyright $\odot 2008$ S. Karger AG, Basel
\end{abstract}

(C) 2008 S. Karger AG, Basel

$1015-9770 / 08 / 0262-0097 \$ 24.50 / 0$

Fax +41613061234

E-Mail karger@karger.ch

www.karger.com

\section{Introduction}

Despite the rapid progress in stroke management during the past decade, stroke has remained a major cause of death and disability in the world. Ischemic stroke occurs when there is a lack of blood flow to the brain. Abundant evidence shows that poor cerebral perfusion is related to unfavorable functional outcome, further strokes and other vascular events [1-4]. Although a number of major clinical studies have demonstrated the benefit of plaque stabilization $[5,6]$ and antithrombotic therapy [7, 8], these medications are mainly for secondary stroke prevention. As the main problem of stroke is that there is not enough blood getting to the focal cerebral region, cerebral blood flow $(\mathrm{CBF})$ augmentation may be the first and most important goal in acute stroke management.

Basically, improving the CBF can be accomplished in 2 broad ways: opening arteries directly by mechanical techniques or augmenting the CBF by systemic strategies. Thrombolytic therapy is the only universally accepted acute treatment for ischemic stroke but the limited time window confines its use to very few patients. New strategies to expand the systemic reperfusion including extending the intravenous rt-PA window to $270 \mathrm{~min}$; new fibrinolytic agents (desmoteplase); combination of lytics, antithrombotics as well as neuroprotectans; and externally applied ultrasound to enhance enzymatic fibrinolysis are currently under investigation $[9,10]$. Alternative options also include balloon angioplasty with or without

\footnotetext{
Dr. Ka Sing Wong

Department of Medicine and Therapeutics

Prince of Wales Hospital

Shatin, Hong Kong

Tel. +852 2632 3144, Fax +852 2649 3761, E-Mail ks-wong@cuhk.edu.hk
} 
stenting $[11,12]$ and mechanical clot retrieval $[13,14]$ in selected patients who presented after the 3 -hour window for intravenous thrombolysis and up to $8 \mathrm{~h}$ after symptom onset or did not respond to t-PA. Although the results are enticing, these approaches are invasive and remain experimental. Under such circumstances, the need for a safe, convenient and effective way of increasing cerebral perfusion by systematic strategies seems obvious.

Diastolic counterpulsation is an acceptable method that is known to improve the perfusion of vital organs. Clinically, diastolic counterpulsation has been achieved invasively with an intra-aortic balloon pump (IABP) or noninvasively by external counterpulsation (ECP). In the early 1960s, Moulopoulus et al. [15] developed an experimental prototype of the IABP. The effects of the IABP are based on the intermittent inflation of a balloon in the descending aorta at the beginning of the diastole when the heart is at rest and deflation at the end of the diastole just before the heart begins to beat. The hemodynamic effects of IABP are a reduction in cardiac afterload and an increase in diastolic blood flow to various organs [16]. IABP is now the most widely used mechanical circulatory assist device for patients with cardiogenic shock. However, its clinical application is limited because of the risks (ipsilateral lower extremity ischemia, arterial embolization, infection, trauma to the aorta or pseudoaneurysm and hemolysis) associated with this invasive technique [17].

ECP operates by applying an ECG-triggered diastolic pressure of approximately $250 \mathrm{~mm} \mathrm{Hg}$ to the calves, thighs and buttocks by means of air-filled cuffs. The diastolic augmentation of the blood flow and the simultaneously decreasing systolic afterload therefore increase the blood flow to the heart, brain and kidneys. As ECP offers a completely noninvasive way of bringing about similar hemodynamic modification, it has become widely used in clinical settings. Consequently, as ECP may improve the cerebral blood blow, it has been proposed as a potential therapy for patients with brain ischemia.

This review will introduce the development of the technique of counterpulsation, investigate its effect on cerebral circulation, evaluate its potential therapeutic role in cerebrovascular disease and further explore its possible mechanisms.

\section{IABP and Cerebrovascular Disease}

Although mainly used in patients with cardiac disease, there is mounting direct or indirect evidence that counterpulsation may enhance the CBF. In 1972, Sime- one et al. [18] first reported a progressive rise in CBF after initiation of IABP in adult rhesus monkeys. Animal studies also demonstrated an increase in CBF in experimental cardiogenic shock canines after IABP. Bhayana et al. [19] measured the $\mathrm{CBF}$ in 13 dogs by radioactive microsphere technique and found that it increased by $56 \%$, while a rise in CBF by $31 \%$ was documented in another evaluation using the same method [20].

An improvement in cerebral perfusion after counterpulsation has been reported by an extended series of studies in both animals and humans suffering from cerebral vasospasm after subarachnoid hemorrhage. Nussbaum et al. [21] reported an average increase in mean CBF of approximately $20 \%$ (ranging from 7 to 50 ) in 10 of 10 dogs after treatment with IABP in a 2-hemorrhage model of cerebral vasospasm. More impressively, the highest value of increase was noted in the dog that developed clinical evidence of focal ischemia. Shortly afterwards, 2 case reports also illustrated the ability of IABP to improve the clinical outcome as well as CBF in patients suffering from vasospam after subarachnoid hemorrhage $[22,23]$. Nussbaum et al. [23] reported that in the case of a 60 -year-old woman with cerebral vasospam induced by subarachnoid hemorrhage who failed to respond to $3 \mathrm{H}$ therapy (hypertension, hypervolemia, hemodilution), the CBF improved by $69.3 \%$ on average after IABP.

In 1989, Tranmer et al. [24] investigated CBF changes after IABP in a cerebral ischemia model after internal carotid artery and middle cerebral artery occlusion, which is the first published paper utilizing counterpulsation therapy in acute ischemic stroke. A 15\% mean increase in CBF in 4 of 6 dogs was documented and among 4 dogs with significant rises in cardiac output, the local $\mathrm{CBF}$ in the ischemic brain increased significantly from $22 \pm 12$ to $26 \pm 11 \mathrm{ml} / 100 \mathrm{~g} / \mathrm{min}$. Although there are compelling data showing the ability of IABP to improve brain perfusion in the situation of cerebral ischemia, most probably due to its invasiveness, there are no published studies evaluating its effect in patients with acute ischemic stroke.

\section{Overview of ECP Therapy}

\section{Historical Development of ECP}

Taking a cue from IABP, the concept of ECP was originally conceived by Dr. Harry Soroff and Dr. William Birtwell at Harvard University in the 1960s. The early device was built at the beginning of the 1970s and consisted of large steel chambers that housed inflatable cuffs,
98

Cerebrovasc Dis 2008;26:97-105
Han/Wong 
which were part of a hydraulic circuit. The device was cumbersome and had a marginal counterpulsation effect. Since then, the machine has been modified several times and its current form is a pneumatic system developed in China in 1983 [25].

During counterpulsation therapy, the patients lie on a treatment table and a series of 3 compressive cuffs are placed on their calves, thighs and buttocks. The machine operates by applying an ECG-triggered diastolic pressure of approximately $250 \mathrm{~mm} \mathrm{Hg}$ to the vascular bed of the calves, thighs and buttocks by means of 3 pairs of airfilled cuffs. A course of ECP treatment usually consists of 35 daily 1-hour sessions over a 7 -week period. To the best of our knowledge, no clinical study or even animal model assessment has ever been carried out to explore whether ECP therapy has a different therapeutic effect under a different duration of treatment. However, in most clinical and animal analyses, $35 \mathrm{~h}$ of treatment appears to be a routine practice [26-30].

\section{Clinical Applications and Contraindications of ECP}

Clinical trials of ECP date back to the 1960s and most of them have focused on the application of ECP in patients with ischemic heart disease. The benefits associated with ECP include reduction of angina and nitrate use, increased exercise tolerance, prolongation of the time to exercise-induced ST segment depression and an accompanying resolution of myocardial perfusion defects [27-30]. By 1995, enough of a body of research had accumulated for ECP to receive FDA approval as a treatment for chronic stable angina.

A prospective, randomized study recently investigated the impact of ECP on retinal reperfusion in patients with acute central retinal artery occlusion or branch retinal artery occlusion. A significant increase in perfusion as measured by scanning laser Doppler flowmetry was observed immediately after $2 \mathrm{~h}$ of ECP in the ischemic retinal area, whereas there was no significant change in the control group [31]. A case report also showed the clinical benefit of ECP for patients with restless legs syndrome, a disorder assumed to be associated with a decrease in vascular flow to the peripheral or central nervous system [32].

ECP treatment is relatively safe. The main side effects include skin abrasion, low back pain and muscle ache. However, there are certain conditions that require caution when considering the therapy: (1) severe aortic insufficiency or aortic dissection; (2) atrial fibrillation or frequent ventricular premature beats that would interfere with ECP triggering; (3) blood pressure persistently
$>180 / 110 \mathrm{~mm} \mathrm{Hg}$; (4) severe symptomatic peripheral vascular disease; (5) history of varicosities, deep vein thrombosis, thrombophlebitis or stasis ulcer; (6) bleeding diathesis and concurrent warfarin use, and (7) presence of active malignancy.

\section{Possible Mechanisms of ECP}

Despite the increasing evidence suggesting the clinical benefits of ECP therapy for angina, the mechanisms behind are largely unknown. The possible factors responsible for its clinical improvement are summarized as follows.

\section{Effects of ECP on Hemodynamic Changes}

The sequential cuff inflation at the beginning of the diastole shifts the blood from the lower extremities toward the aorta and at the same time creates a retrograde pressure wave that augments the diastolic blood pressure (diastolic augmentation) as well as the mean arterial blood pressure, while the simultaneous deflation at the end of the diastole removes all the externally applied pressure to allow forward flow of blood, leaving behind an empty vascular bed in the lower limb to receive the output of the heart. Therefore, the systolic blood pressure (systolic unloading) and cardiac afterload are reduced. The magnitude of hemodynamic changes generated by ECP can be estimated by measuring the diastolic to systolic effectiveness ratio using finger plethysmography (peak diastolic amplitude divided by speak systolic amplitude). Doppler echocardiographic studies found that a ratio of 1.5-2.0 during the procedure may lead to an optimal increase in both diastolic anterograde and diastolic retrograde aortic flow [33]. However, as some patients who had clinical improvement do not achieve a ratio of 1.5-2.0, the clinical significance of this finding is yet uncertain $[34,35]$. The magnitude of diastolic augmentation that can be achieved with ECP was found to be comparable to that of the IABP [36]. Unlike IABP, ECP also augments the venous return through the compression of the capacitance vein of the lower limbs, further promoting a $25 \%$ increase in cardiac output. These hemodynamic effects result in a rise in blood flow in multiple vascular beds, including the brain, kidneys, liver and myocardium $[34,37,38]$.

\section{Effect of ECP on Collateral Circulation}

Apart from the hemodynamic changes during ECP, establishing a good collateral circulation may contribute to its long-term benefit. Basically there are 2 ways of enhancing collateral perfusion: one is opening or expand- 
ing the preformed vessels, and the other one is the formation of new vessels. It is believed that chronic exposure of the vascular bed to the augmented blood flow may increase vascular shear stress $[39,40]$, and enhanced shear stress itself plays an important role in the maintenance of a functional endothelium [41]. A recent study found that ECP reduces endothelial damage, arrests vascular smooth muscle cell proliferation and migration, decreases the proliferating cell nuclear antigen proliferative index, suppresses extracellular matrix formation, and eventually inhibits intimal hyperplasia and the development of atherosclerosis by increasing the arterial wall shear stress, which in turn activates the endothelial-derived nitric oxide (NO) synthase/NO pathway and probably suppresses extracellular signal-regulated kinase $1 / 2$ overactivation [42]. In addition, other studies have shown that increased shear stress stimulates the release of NO, which is a vasodilator, and on the other hand, inhibits the release of endothelial endothelin-1 (ET-1), which is a vasoconstrictor. Barsness [26] reported a significant increase in plasma NO levels and a decrease in ET-1 levels after a course of ECP among patients with ischemic heart disease. Another study found the rise in plasma NO levels persist 1 month after the completion of 35 one-hour sessions of ECP [27]. Such changes in the release of sheardependent vasomediators as well as augmented arterial pressure may help open the preformed collateral channels, which is the simplest way to augment collateral perfusion.

On the other hand, an increase in shear stress produced by ECP may influence angiogenesis, which may also improve collateral perfusion. Apart from ischemia, a rise in endothelial shear stress produced by ECP due to a chronic exposure of the arterial bed to the augmented blood flow is considered a major stimulus for collateral development [43]. Increased shear stress may upregulate the endothelial production of growth factors, such as vascular endothelial growth factor (VEGF), which plays a key role in angiogenesis [44]. In a case series of 11 patients with stable angina, a significant rise in the plasma level of VEGF was noted [45]. Furthermore, an increase in plasma VEGF levels was reported in 5 patients with chronic angina who achieved a 50\% reduction in anginal episodes after a course of ECP, whereas no change was found in 4 patients without response [26]. However, all evidence of biomarker changes now comes from patients with ischemic heart disease. Although stroke patients are most likely to derive clinical benefit through the same mechanisms, evidence of such changes in stroke patients is not available to date.

\section{ECP and Cerebrovascular Disease}

\section{Evidence of Improvement in Brain Perfusion}

ECP-induced hemodynamic effects result in diastolic augmentation, systemic unloading and also an increase in cardiac output, therefore augmenting the blood flow in multiple vascular beds. Recently, a number of investigations have evaluated the effect of ECP on cerebral circulation by means of carotid duplex or transcranial Doppler ultrasonography. A study from the USA reported that the mean carotid flow velocity integral increased by $22 \%$ from $27.7 \pm 1.8$ to $33.1 \pm 2.3 \mathrm{~cm} / \mathrm{s}$ during ECP, with an average peak carotid diastolic flow velocity of 56 $\mathrm{cm} / \mathrm{s}$, which is $75 \%$ as high as the systolic wave [46]. Werner et al. [37] noted a $19 \%$ rise in flow volume in the carotid artery and a $12 \%$ increase in the vertebral artery during ECP. The same research team [47] further reported an augmented flow during the diastole in the middle cerebral artery immediately after the start of ECP in both healthy controls and patients with severe atherosclerosis.

\section{ECP Therapy for Cerebrovascular Disease in China}

Because ECP has a potential effect in improving brain perfusion, it is plausible that it will be beneficial for patients with cerebrovascular disease. Physicians in China began treating stroke patients with ECP in the late 1980s. After an extensive search of the MEDLINE (1966-2004) database, no paper published in the English literature was found to evaluate the therapeutic effect of ECP for stroke patients. We then systematically identified and reviewed all articles published in the Chinese literature in the Wan Fang and China Academic Journal databases (2 major national databases in China) during the past 2 decades. Twenty-two papers were identified and all reported a favorable outcome. Table 1 lists the research discussed in this article, together with details of the study design, etc. Apart from the clinical improvement, a number of investigations recorded an increase in brain perfusion after ECP treatment $[48,49]$. In a randomized-controlled study, the average CBF was found to be $45.7 \pm 6.0 \mathrm{ml} / 100 \mathrm{~g} / \mathrm{min}$ before versus $55.6 \pm 6.0 \mathrm{ml} / 100 \mathrm{~g} / \mathrm{min}$ after ECP in the treatment group $(n=40)$, while in the non-ECP group no significant change was found $(\mathrm{n}=40)$. In addition, $29 \mathrm{pa-}$ tients (72.5\%) in the ECP group, compared to only 22 (55\%) in the control group, had a favorable clinical outcome [50].

Studies also show a significant decrease in hematocrit, fibrinogen level and plasma viscosity after $12-35 \mathrm{~h}$ of ECP [51-55], which may result in an increase in CBF [56, 
Table 1. Chinese studies on the effects of ECP in patients with ischemic stroke

\begin{tabular}{|c|c|c|c|c|}
\hline Study & Study design & Participants & Intervention & Outcome measurement \\
\hline $\begin{array}{l}\text { Zhao et al. [60], } \\
1988\end{array}$ & $\begin{array}{l}\text { dual arm, } \\
\text { randomized-controlled }\end{array}$ & $\begin{array}{l}\operatorname{ECP}(\mathrm{n}=24) \\
\text { non-ECP }(\mathrm{n}=24) \\
\text { stroke }(\mathrm{n}=48)\end{array}$ & $12 \mathrm{~h} \mathrm{ECP}$ & $\begin{array}{l}\text { favorable clinical outcome } \\
(100 \text { vs. } 75 \%, p<0.01)\end{array}$ \\
\hline $\begin{array}{l}\text { Zhen and } \\
\text { Gong [61], } \\
1988\end{array}$ & $\begin{array}{l}\text { dual arm, } \\
\text { nonrandomized }\end{array}$ & $\begin{array}{l}\operatorname{ECP}(\mathrm{n}=24) \\
\text { non-ECP }(\mathrm{n}=24) \\
\text { stroke }(\mathrm{n}=48)\end{array}$ & $12-36 \mathrm{~h}$ ECP & $\begin{array}{l}\text { favorable clinical outcome } \\
(95.8 \text { vs. } 75 \%, p<0.05)\end{array}$ \\
\hline $\begin{array}{l}\mathrm{Wu}[62] \\
1990\end{array}$ & $\begin{array}{l}\text { dual arm, } \\
\text { nonrandomized }\end{array}$ & $\begin{array}{l}\operatorname{ECP}(\mathrm{n}=75) \\
\text { non-ECP }(\mathrm{n}=70) \\
\text { stroke }(\mathrm{n}=145)\end{array}$ & $12-24 \mathrm{~h}$ ECP & $\begin{array}{l}\text { favorable clinical outcome } \\
\text { ( } 78.7 \text { vs. } 55.7 \%, \mathrm{p}<0.01 \text { ) }\end{array}$ \\
\hline $\begin{array}{l}\text { Zhong et al. [63], } \\
1990\end{array}$ & $\begin{array}{l}\text { dual arm, } \\
\text { randomized-controlled }\end{array}$ & $\begin{array}{l}\operatorname{ECP}(\mathrm{n}=22) \\
\text { non-ECP }(\mathrm{n}=22) \\
\text { stroke }(\mathrm{n}=44)\end{array}$ & $12 \mathrm{~h} \mathrm{ECP}$ & $\begin{array}{l}\text { favorable clinical outcome ( } 94.1 \text { vs. } \\
64.7 \%, \mathrm{p}<0.05) ; 95.4 \% \text { had } \gamma-\mathrm{CBF} \\
\text { increase in the ECP group }\end{array}$ \\
\hline $\begin{array}{l}\text { Li et al. [53], } \\
1994\end{array}$ & case series & $\begin{array}{l}\operatorname{CAD}(\mathrm{n}=20) \\
\text { stroke }(\mathrm{n}=8) \\
\text { atherosclerosis }(\mathrm{n}=20)\end{array}$ & $1 \mathrm{~h} \mathrm{ECP}$ & plasma viscosity $\downarrow(\mathrm{p}<0.05)$ \\
\hline $\begin{array}{l}\text { Chen et al. [51], } \\
1994\end{array}$ & case series & $\begin{array}{l}\text { CAD }(n=27) \\
\text { stroke }(n=18) \\
\text { atherosclerosis }(n=48)\end{array}$ & $1 \mathrm{~h} \mathrm{ECP}$ & plasma viscosity $\downarrow(\mathrm{p}<0.05)$ \\
\hline $\begin{array}{l}\text { Chen et al. [64], } \\
1994\end{array}$ & $\begin{array}{l}\text { dual arm, } \\
\text { randomized-controlled }\end{array}$ & $\begin{array}{l}\operatorname{ECP}(\mathrm{n}=74) \\
\text { non-ECP }(\mathrm{n}=44) \\
\text { stroke }(\mathrm{n}=118)\end{array}$ & $\begin{array}{l}12 \text { h ECP + dextran } 40 \\
\text { vs. dextran } 40\end{array}$ & $\begin{array}{l}\text { favorable clinical outcome } \\
(64.1 \text { vs. } 25 \%, \mathrm{p}<0.01)\end{array}$ \\
\hline $\begin{array}{l}\text { Yao et al. [49], } \\
1996\end{array}$ & case series & $\begin{array}{l}\text { TIA }(n=10) \\
\text { atherosclerosis }(n=12)\end{array}$ & 24-36 h ECP & $72.2 \%$ had $\gamma$-CBF increase \\
\hline $\begin{array}{l}\text { Xu et al. [65], } \\
1996\end{array}$ & dual arm, self-controlled & $\begin{array}{l}\text { stroke }(\mathrm{n}=20) \\
\text { controls }(\mathrm{n}=10)\end{array}$ & $1 \mathrm{~h} \mathrm{ECP}$ & $\begin{array}{l}\text { t-PA } \uparrow \text { in both groups, } \\
\mathrm{D} \text {-dimer } \uparrow \text { in stroke patients, } \\
\text { no change in PAI in both groups }\end{array}$ \\
\hline $\begin{array}{l}\text { Yang et al. [50], } \\
1996\end{array}$ & $\begin{array}{l}\text { dual arm, } \\
\text { randomized-controlled, } \\
\text { assessment-blinded }\end{array}$ & $\begin{array}{l}\operatorname{ECP}(\mathrm{n}=40) \\
\text { non-ECP }(\mathrm{n}=40) \\
\text { stroke }(\mathrm{n}=80)\end{array}$ & $12 \mathrm{~h} \mathrm{ECP}$ & $\begin{array}{l}\text { favorable clinical outcome }(72.5 \text { vs. } 55 \% \text {, } \\
\mathrm{p}<0.01) ; \gamma \text {-CBF increased by } 17.8 \% \text { in } \\
\text { the ECP group }\end{array}$ \\
\hline $\begin{array}{l}\text { He et al. [66], } \\
1996\end{array}$ & case series & stroke $(\mathrm{n}=184)$ & $12-72 \mathrm{~h}$ ECP & $95.1 \%$ had a favorable clinical outcome \\
\hline $\begin{array}{l}\text { Du et al. [52], } \\
2000\end{array}$ & $\begin{array}{l}\text { dual arm, } \\
\text { nonrandomized }\end{array}$ & $\begin{array}{l}\operatorname{ECP}(\mathrm{n}=40) \\
\text { non-ECP }(\mathrm{n}=40) \\
\text { stroke }(\mathrm{n}=80)\end{array}$ & 24-36 h ECP & $\begin{array}{l}\text { favorable clinical outcome ( } 95 \text { vs. } 75 \% \text {, } \\
\text { p }<0.05 \text { ); plasma viscosity } \downarrow \text { in both } \\
\text { groups, HCT } \downarrow \text { and FIB } \downarrow \text { in the ECP } \\
\text { group }\end{array}$ \\
\hline $\begin{array}{l}\text { Meng et al. [67], } \\
2000\end{array}$ & $\begin{array}{l}\text { dual arm, } \\
\text { randomized-controlled }\end{array}$ & $\begin{array}{l}\operatorname{ECP}(\mathrm{n}=70) \\
\text { non-ECP }(\mathrm{n}=68) \\
\text { stroke }(\mathrm{n}=138)\end{array}$ & $\begin{array}{l}24 \text { h ECP + dextran } 40 \\
\text { vs. dextran } 40\end{array}$ & $\begin{array}{l}\text { favorable clinical outcome ( } 92.9 \text { vs. } \\
73.5 \%, \mathrm{p}<0.05)\end{array}$ \\
\hline $\begin{array}{l}\text { Niu et al. [58], } \\
2000\end{array}$ & $\begin{array}{l}\text { dual arm, } \\
\text { randomized-controlled }\end{array}$ & $\begin{array}{l}\operatorname{ECP}(n=20) \\
\text { non-ECP }(n=22) \\
\text { stroke }(n=42)\end{array}$ & $\begin{array}{l}12 \text { h ECP + dextran } 40 \\
\text { vs. dextran } 40\end{array}$ & $\begin{array}{l}\text { SOD } \downarrow, \mathrm{MDA} \downarrow \text { and ET- } 1 \downarrow \text { in the ECP } \\
\text { group }\end{array}$ \\
\hline $\begin{array}{l}\text { He and } \mathrm{Xu}[68] \\
2000\end{array}$ & case series & stroke $(\mathrm{n}=20)$ & $12-36$ h ECP & $60 \%$ had a favorable clinical outcome \\
\hline $\begin{array}{l}\text { Ma et al. [69], } \\
2000\end{array}$ & case series & stroke $(\mathrm{n}=241)$ & $10-50 \mathrm{~h} \mathrm{ECP}$ & $97.1 \%$ had a favorable clinical outcome \\
\hline $\begin{array}{l}\text { Liu and Zhou [70], } \\
2001\end{array}$ & case series & stroke $(\mathrm{n}=30)$ & $\begin{array}{l}\text { defibrase } 10 \mathrm{U} \text { i.v. for } 3 \text { days, } \\
\text { followed by } 12 \mathrm{~h} \mathrm{ECP}\end{array}$ & 93.3\% had a favorable clinical outcome \\
\hline $\begin{array}{l}\text { Zhang [71], } \\
2001\end{array}$ & $\begin{array}{l}\text { dual arm, } \\
\text { randomized-controlled }\end{array}$ & $\begin{array}{l}\mathrm{ECP}(\mathrm{n}=24) \\
\text { non-ECP }(\mathrm{n}=24) \\
\text { stroke }(\mathrm{n}=48)\end{array}$ & $\begin{array}{l}12 \text { h ECP + dextran } 40 \\
\text { vs. dextran } 40\end{array}$ & $\begin{array}{l}\text { favorable clinical outcome } \\
(95.8 \text { vs. } 75 \%, p<0.05)\end{array}$ \\
\hline
\end{tabular}


Table 1 (continued)

\begin{tabular}{|c|c|c|c|c|}
\hline Study & Study design & Participants & Intervention & Outcome measurement \\
\hline $\begin{array}{l}\text { Wu et al. [48], } \\
2001\end{array}$ & $\begin{array}{l}\text { dual arm, } \\
\text { randomized-controlled, } \\
\text { assessment-blinded }\end{array}$ & $\begin{array}{l}\operatorname{ECP}(n=30) \\
\text { non-ECP }(n=30) \\
\text { atherosclerosis }(n=60)\end{array}$ & $72 \mathrm{~h} \mathrm{ECP}$ & $\begin{array}{l}\gamma \text {-CBF increased by } 17.2 \% \text { in the ECP } \\
\text { group; no change noted in the control } \\
\text { group }\end{array}$ \\
\hline $\begin{array}{l}\text { Yao }[54] \\
2003\end{array}$ & $\begin{array}{l}\text { dual arm, } \\
\text { nonrandomized, } \\
\text { self-controlled }\end{array}$ & $\begin{array}{l}\operatorname{ECP}(n=118) \\
\text { non-ECP }(n=68) \\
\text { stroke }(n=186)\end{array}$ & $\begin{array}{l}24 \mathrm{~h} \text { ECP }+ \text { dextran } 40 \\
\text { vs. dextran } 40\end{array}$ & $\begin{array}{l}\text { favorable clinical outcome } \\
(96.0 \text { vs. } 83.8 \%, p<0.05) \\
\text { Plasma viscosity } \downarrow \text { in the ECP group }\end{array}$ \\
\hline $\begin{array}{l}\text { Liu et al. [72], } \\
2003\end{array}$ & $\begin{array}{l}\text { dual arm, } \\
\text { nonrandomized }\end{array}$ & $\begin{array}{l}\operatorname{ECP}(n=60) \\
\text { non-ECP }(n=63) \\
\text { stroke }(n=123)\end{array}$ & $35 \mathrm{~h} \mathrm{ECP}$ & $\begin{array}{l}\text { favorable clinical outcome }(\mathrm{BI}) \text { in the } \\
\text { ECP group vs. control }(\mathrm{p}<0.01)\end{array}$ \\
\hline $\begin{array}{l}\text { Zhang et al. [55], } \\
2003\end{array}$ & $\begin{array}{l}\text { dual arm, } \\
\text { randomized-controlled }\end{array}$ & $\begin{array}{l}\operatorname{ECP}(\mathrm{n}=70) \\
\text { non-ECP }(\mathrm{n}=68) \\
\text { stroke }(\mathrm{n}=138)\end{array}$ & $\begin{array}{l}24 \text { h ECP + dextran } 40 \\
\text { vs. dextran } 40\end{array}$ & $\begin{array}{l}\text { favorable clinical outcome } e^{*}(92.9 \text { vs. } \\
73.5 \%, \mathrm{p}<0.05) \text {; plasma viscosity } \downarrow \text { HCT } \downarrow \\
\text { FIB } \downarrow \text { in the ECP group }\end{array}$ \\
\hline
\end{tabular}

$\mathrm{PAI}=$ Plasminogen activator inhibitor $\mathrm{CAD}=$ coronary artery disease $\mathrm{HCT}=$ hematocrit $\mathrm{SOD}=$ superoxide dismutase MDA = malondialdehyde; $\mathrm{FIB}=$ fibrinogen. Favorable clinical outcome: assessed by Chinese stroke scale (4th version).

57]. More importantly, these changes in biomarkers were accompanied by a clinical improvement $[52,54,55]$. It is of interest that 1 study found a decrease in plasma ET-1 level after ECP treatment among acute stroke patients as previously seen in subjects with angina [58]. ET-1-mediated vasoconstriction further reduced the blood flow in collateral circulation and aggravated the ischemic effect of an existing cerebral lesion, thus, a significant decrease in the ET-1 level may consequently lead to a better clinical outcome. Although the reason behind is unclear, a decrease in the plasma markers of oxidative stress was also shown in these patients [58].

In summary, ECP may improve the neurological outcome by enhancing brain perfusion [48-50], lowering blood viscosity [51-55], as well as regulating vasomediators [58] and oxidative stress [58]. Although the results appeared promising and no serious adverse complications were documented, most of the evidence was based on the findings of observational studies, case series and research with poor design. The methodological issues found in these studies include: the relatively small sample size, the lack of an appropriate control group, the variation in the treatment duration, the use of nonstandard outcome measurements and the lack of information on the method of blindness in the study design. The treatment duration varied from trial to trial, ranging from 1 to $50 \mathrm{~h}$, even in the same study the treatment sessions were not identical. In addition, instead of using standard outcome measurements, such as NIHSS and modified Rankin Scale, most studies used the Chinese Stroke Scale or other surrogate biomarkers to assess the outcome.
These shortcomings of the existing literatures greatly weaken the credibility of the therapeutic effect of ECP on ischemic stroke. Therefore, these studies could only be used as evidence to support the clinical benefit of ECP among stroke patients in anything more than a very general way.

\section{Conclusions}

From the results of the studies to date, there is evidence to suggest that ECP may enhance the blood supply to the brain. Therefore, we feel there is a rationale that ECP may be beneficial to patients with ischemic stroke. Currently, ECP is a well-established adjunctive treatment for chronic angina, but there have been very few experiences in stroke treatment. Although the quality of the studies done in China is generally poor, the preliminary data suggested that ECP might improve the clinical outcome of ischemic stroke. Well-designed clinical trials exploring the therapeutic effects of ECP in ischemic stroke are very limited at the current stage. Our randomized, crossover, assessment-blinded pilot study showed that ECP was safe and feasible for stroke patients with large artery disease [59]. Randomized-controlled trials with a large sample size are definitely needed to define the efficacy and safety of ECP in acute stroke management. Also, it is important to identify which patients benefit the most from ECP treatment as well as the time window for initiating the therapy after symptom onset. Further, we should be aware that in a device-related clin- 
ical trial, it is impossible to fully blind the patients as well as the personnel carrying out the treatment. In the Multicenter Study of Enhanced External Counterpulsation trial, a pressure of $75 \mathrm{~mm} \mathrm{Hg}$ was applied to the sham control group, whereas the active group used a pressure of $300 \mathrm{~mm} \mathrm{Hg}$. The mask is not effective as some of the patients correctly guess their form of treatment [28]. The only way to conduct the trial is to have a blinded rater, who assesses the patients independently during the follow-up period, as was done in the t-PA trials. Finally, more has to be learned about the mechanisms responsible for its clinical benefit, especially the real-time CBF during ECP, as well as changes in biomarkers that may help establish a good collateral circulation in the long term.

\section{References}

- 1 Ho SS, Lam WW, Wong KS, Leung CS, Metreweli C: Potential value of poststroke extracranial arterial blood flow volume in the prediction of stroke functional outcome. Cerebrovasc Dis 2006;21:54-59.

$\checkmark 2$ North American Symptomatic Carotid Endarterectomy Trial Collaborators: Beneficial effect of carotid endarterectomy in symptomatic patients with high-grade carotid stenosis. N Engl J Med 1991;325:445453.

$\checkmark 3$ Wong KS, Li H, Chan YL, Ahuja A, Lam WW, Wong A, Kay R: Use of transcranial Doppler ultrasound to predict outcome in patients with intracranial large-artery occlusive disease. Stroke 2000;31:26412647.

$\checkmark 4$ Wong KS, Li H: Long-term mortality and recurrent stroke risk among Chinese stroke patients with predominant intracranial atherosclerosis. Stroke 2003;34:2361-2366.

$\checkmark 5$ Brown BG, Zhao XQ, Sacco DE, Albers JJ: Lipid lowering and plaque regression: new insights into prevention of plaque disruption and clinical events in coronary disease. Circulation 1993;87:1781-1791.

-6 Amarenco P, Bogousslavsky J, Callahan A 3rd, Goldstein LB, Hennerici M, Rudolph AE, Sillesen H, Simunovic L, Szarek M, Welch KM, Zivin JA: High-dose atorvastatin after stroke or transient ischemic attack. N Engl J Med 2006;355:549-559.

$\checkmark 7$ CAPRIE Steering Committee: A randomised, blinded, trial of clopidogrel versus aspirin in patients at risk of ischaemic events (CAPRIE). Lancet 1996;348:1329-1339.

$>8$ International Stroke Trial Collaborative Group: The International Stroke Trial (IST): a randomised trial of aspirin, subcutaneous heparin, both, or neither among 19435 patients with acute ischaemic stroke. Lancet 1997;349:1569-1581.

$\checkmark 9$ Martinez-Sanchez P, Diez-Tejedor E, Fuentes B, Ortega-Casarrubios MA, Hacke W: Systemic reperfusion therapy in acute ischemic stroke. Cerebrovasc Dis 2007;24(suppl 1):143-152.
10 Meairs S, Wahlgren N, Dirnagl U, Lindvall O, Rothwell P, Baron JC, Hossmann K, Engelhardt B, Ferro J, McCulloch J, Kaste M, Endres M, Koistinaho J, Planas A, Vivien D, Dijkhuizen R, Czlonkowska A, Hagen A, Evans A, De Libero G, Nagy Z, Rastenyte D, Reess J, Davalos A, Lenzi GL, Amarenco P, Hennerici M: Stroke research priorities for the next decade - a representative view of the European scientific community. Cerebrovasc Dis 2006;22:75-82.

11 SSYLVIA Study Investigators: Stenting of Symptomatic Atherosclerotic Lesions in the Vertebral or Intracranial Arteries (SSYLVIA): study results. Stroke 2004;35:13881392.

12 Henkes H, Miloslavski E, Lowens S, Reinartz J, Liebig T, Kuhne D: Treatment of intracranial atherosclerotic stenoses with balloon dilatation and self-expanding stent deployment (WingSpan). Neuroradiology 2005;47: 222-228.

13 Gobin YP, Starkman S, Duckwiler GR, Grobelny T, Kidwell CS, Jahan R, Pile-Spellman J, Segal A, Vinuela F, Saver JL: MERCI 1: a phase 1 study of Mechanical Embolus Removal in Cerebral Ischemia. Stroke 2004;35: 2848-2854.

14 Kerber CW, Barr JD, Berger RM, Chopko BW: Snare retrieval of intracranial thrombus in patients with acute stroke. J Vasc Interv Radiol 2002;13:1269-1274.

15 Moulopoulos SD, Topaz S, Kolff WJ: Diastolic balloon pumping (with carbon dioxide) in the aorta - a mechanical assistance to the failing circulation. Am Heart J 1962;63:669675.

16 Powell WJ Jr, Daggett WM, Magro AE, Bianco JA, Buckley MJ, Sanders CA, Kantrowitz AR, Austen WG: Effects of intra-aortic balloon counterpulsation on cardiac performance, oxygen consumption, and coronary blood flow in dogs. Circ Res 1970;26:753764.
7 Gottlieb SO, Brinker JA, Borkon AM, Kallman CH, Potter A, Gott VL, Baughman KL: Identification of patients at high risk for complications of intraaortic balloon counterpulsation: a multivariate risk factor analysis. Am J Cardiol 1984;53:1135-1139.

18 Simeone FA, Laurent JP, Trepper PJ, Brown DJ, Cotter J: Experimental augmentation of cerebral blood flow by intermittent aortic occlusion. J Neurosurg 1972;36:700-713.

19 Bhayana JN, Scott SM, Sethi GK, Takaro T: Effects of intraaortic balloon pumping on organ perfusion in cardiogenic shock. J Surg Res 1979;26:108-113.

20 Wesley R Jr, Morgan DB: Effect of continuous intra-aortic balloon inflation in canine open chest cardiopulmonary resuscitation. Crit Care Med 1990;18:630-633.

21 Nussbaum ES, Heros RC, Solien EE, Madison MT, Sebring LA, Latchaw RE: Intraaortic balloon counterpulsation augments cerebral blood flow in a canine model of subarachnoid hemorrhage-induced cerebral vasospasm. Neurosurgery 1995;36:879884.

22 Apostolides PJ, Greene KA, Zabramski JM, Fitzgerald JW, Spetzler RF: Intra-aortic balloon pump counterpulsation in the management of concomitant cerebral vasospasm and cardiac failure after subarachnoid hemorrhage: technical case report. Neurosurgery 1996;38:056-059; discussion 10591060.

23 Nussbaum ES, Sebring LA, Ganz WF, Madison MT: Intra-aortic balloon counterpulsation augments cerebral blood flow in the patient with cerebral vasospasm: a xenonenhanced computed tomography study. Neurosurgery 1998;42:206-213.

24 Tranmer BI, Peniston C, Iacobacci R, Salerno TA, Hudson AR: Intra-aortic balloon counterpulsation: a treatment for ischaemic stroke? Neurol Res 1989;11:109-113.

25 Zheng ZS, Li TM, Kambic H, Chen GH, Yu LQ, Cai SR, Zhan CY, Chen YC, Wo SX, Chen GW, et al: Sequential external counterpulsation (SECP) in China. Trans Am Soc Artif Intern Organs 1983;29:599-603. 
-26 Barsness GW: Enhanced external counterpulsation in unrevascularizable patients. Curr Interv Cardiol Rep 2001;3:37-43.

-27 Masuda D, Nohara R, Hirai T, Kataoka K, Chen LG, Hosokawa R, Inubushi M, Tadamura E, Fujita M, Sasayama S: Enhanced external counterpulsation improved myocardial perfusion and coronary flow reserve in patients with chronic stable angina; evaluation by ${ }^{13} \mathrm{~N}$-ammonia positron emission tomography. Eur Heart J 2001;22:1451-1458.

-28 Arora RR, Chou TM, Jain D, Fleishman B, Crawford L, McKiernan T, Nesto RW: The multicenter study of enhanced external counterpulsation (MUST-EECP): effect of EECP on exercise-induced myocardial ischemia and anginal episodes. J Am Coll Cardiol 1999;33:1833-1840.

-29 Barsness G, Feldman AM, Holmes DR Jr, Holubkov R, Kelsey SF, Kennard ED: The International EECP Patient Registry (IEPR): design, methods, baseline characteristics, and acute results. Clin Cardiol 2001;24:435442.

-30 Lawson WE, Hui JC, Lang G: Treatment benefit in the enhanced external counterpulsation consortium. Cardiology 2000;94:3135.

-31 Werner D, Michalk F, Harazny J, Hugo C, Daniel WG, Michelson G: Accelerated reperfusion of poorly perfused retinal areas in central retinal artery occlusion and branch retinal artery occlusion after a short treatment with enhanced external counterpulsation. Retina 2004;24:541-547.

-32 Rajaram SS, Shanahan J, Ash C, Walters AS, Weisfogel G: Enhanced external counter pulsation (EECP) as a novel treatment for restless legs syndrome (RLS): a preliminary test of the vascular neurologic hypothesis for RLS. Sleep Med 2005;6:101-106.

-33 Suresh K, Simandl S, Lawson WE, Hui JC, Lillis O, Burger L, Guo T, Cohn PF: Maximizing the hemodynamic benefit of enhanced external counterpulsation. Clin Cardiol 1998;21:649-653.

-34 Michaels AD, Kennard ED, Kelsey SE, Holubkov R, Soran O, Spence S, Chou TM: Does higher diastolic augmentation predict clinical benefit from enhanced external counterpulsation? Data from the International EECP Patient Registry (IEPR). Clin Cardiol 2001; 24:453-458.

-35 Lakshmi MV, Kennard ED, Kelsey SF, Holubkov R, Michaels AD: Relation of the pattern of diastolic augmentation during a course of enhanced external counterpulsation (EECP) to clinical benefit [from the International EECP Patient Registry (IEPR)]. Am J Cardiol 2002;89:1303-1305.

-36 Taguchi I, Ogawa K, Oida A, Abe S, Kaneko N, Sakio H: Comparison of hemodynamic effects of enhanced external counterpulsation and intra-aortic balloon pumping in patients with acute myocardial infarction. Am J Cardiol 2000;86:1139-1141, A1139.
50 Yang SJ, Gu DX, Li F, Cao ZZ, Shi JM: Assessment of cerebral blood flow by TCD and $\gamma$ $\mathrm{CBF}$ in patients with ischemic stroke after external counterpulsation (in Chinese). Xian Dai Yi Xue Yi Qi Yu Ying Yong 1996;8:1618.

51 Chen RY, Xu FL: Change in blood viscosity after external counterpulsation in patients with cardiovascular and cerebrovascular disease (in Chinese). Wei Xun Huan Xue Za Zhi 1993;5:50-51.

$52 \mathrm{Du}$ LJ, Zhang LJ, Hu Y: Clinical improvement in ischemic stroke patients after external counterpulsation (in Chinese).Yi Xue Li Lun Yu Shi Jian 2000;13:740-741.

53 Li L, Wei XD, Yang HY: Effect of external counterpulsation on platelet aggregation and blood viscosity (in Chinese). Wei Xun Huan Xue Za Zhi 1994;5:32-33.

54 Yao DR: External counterpulsation in patients with chronic ischemic stroke (in Chinese). Si Shuan Yi Xue 2003;24:590-591.

55 Zhang JL, Jiang LW, Li XZ: Effect of external counterpulsation on cerebral hemodynamics among patients with ischemic stroke (in Chinese). Xin Xue Guan Kang Fu Yi Xue Za Zhi 2003;12:242-243. hanced external counterpulsation inhibits intimal hyperplasia by modifying shear stress responsive gene expression in hypercholesterolemic pigs. Circulation 2007;116: 526-534.

43 Kersten JR, Pagel PS, Chilian WM, Warltier DC: Multifactorial basis for coronary collateralization: a complex adaptive response to ischemia. Cardiovasc Res 1999;43:44-57.

44 Gan L, Miocic M, Doroudi R, Selin-Sjogren $\mathrm{L}$, Jern S: Distinct regulation of vascular endothelial growth factor in intact human conduit vessels exposed to laminar fluid shear stress and pressure. Biochem Biophys Res Commun 2000;272:490-496.

45 Masuda D, Nohara K, Kataoka K, Hosokawa R, Kanbara N, Fujita M: Enhanced external counterpulsation promotes angiogenesis factors in patients with chronic stable angina (abstract). Circulation 2001;104:II445.

-46 Applebaum RM, Kasliwal R, Tunick PA, Konecky N, Katz ES, Trehan N, Kronzon I: Sequential external counterpulsation increases cerebral and renal blood flow. Am Heart J 1997; 133:611-615.

47 Werner D, Marthol H, Brown CM, Daniel WG, Hilz MJ: Changes of cerebral blood flow velocities during enhanced external counterpulsation. Acta Neurol Scand 2003;107: 405-411.

48 Wu RL, Shi SR, Ge HF, Shao Y, Cai DW: Effect of external counterpulsation on focal cerebral blood flow (in Chinese). Nao Yu Shen Jing Ji Bing Za Zhi 2001;9:284-286.

49 Yao WX, Chang GJ, Xu ZQ, Ma YQ, Lin Z, Bao LH, Li YJ, Xu F: Evaluation of brain perfusion by SPECT after external counterpulsation in patients with ischemic stroke (in Chinese). He Ji Shu 1996;19:677-678.
56 Thomas DJ, Marshall J, Russell RW, Wetherley-Mein G, du Boulay GH, Pearson TC, Symon L, Zilkha E: Effect of haematocrit on cerebral blood-flow in man. Lancet 1977;2: 941-943.

57 Tohgi H, Yamanouchi H, Murakami M, Kameyama M: Importance of the hematocrit as a risk factor in cerebral infarction. Stroke 1978;9:369-374.

58 Niu JZ, Qu HX, Zhu WB: Changes in plasma ET, MDA and SOD level in patients with acute ischemic stroke after external counterpulsation (in Chinese). Shan Dong Yi Yao 2000;40:11-12.

59 Han JH, Leung TW, Lam WW, Soo YO, Alexandrov AV, Mok V, Leung YF, Lo R, Wong KS: Preliminary findings of external counterpulsation for ischemic stroke patient with large artery occlusive disease. Stroke 2008; 39:1340-1343.

60 Zhao GL, Li S, Wang ZY, Qian SW, Chen SW, Chen SL, Chen XQ: An observational study of external counterpulsation for ischemic stroke (in Chinese). Zhong Guo Ti Wai Fan Bo Za Zhi. 1988;1:12-14.

61 Zhen R, Gong DS: Treatment of external counterpulsation in ischemic stroke (in Chinese). Zhong Guo Ti Wai Fan Bo Za Zhi 1988; 1:17-18.

$62 \mathrm{Wu}$ ZL: A study on clinical improvement of ischemic stroke patients after external counterpulsation (in Chinese). Zhong Guo Ti Wai Fan Bo Za Zhi 1990;1:15-16.

63 Zhong GL, Wang ZY, Chen HY, Li S, Qian SW, Zhu JR, Zhao HY, Yuan AN: Enhancement of focal cerebral perfusion after external counterpulsation (in Chinese). Zhong Guo Ti Wai Fan Bo Za Zhi 1990;1:1-5. 
64 Chen ZX, Liu HL, Tao GW: Effect of external counterpulsation in 74 patients with lacunar stroke and cerebral artery atherosclerosis an observational study (in Chinese). Guang Dong Yi Xue Yuan Xue Bao 1994;12:231232.

65 Xu JM, Niu JZ, Zhu WB, Yuan MM, Wang JM, Cai NS: Changes in plasma levels of t-PA, PAI and D-dimer in ischemic stroke patients after external counterpulsation (in Chinese). Shang Hai Yi Ke Da Xue Xue Bao 1996;23: 19-21.

66 He GP, Zhong YX, Diao FY, Fu YP, Jing YP: External counterpulsation in patients with ischemic stroke (in Chinese). Hei Long Jiang Yi Xue 1996;149:12-13.
67 Meng ZW, Hu Y, Jiang LW, Li XZ: Clinical recovery of ischemic stroke patients after external counterpulsation (in Chinese). Xian Dai Kang Fu 2000;4:894.

$68 \mathrm{He}$ MZ, Xu YS: Clinical benefit of external counterpulsation in ischemic stroke patients (in Chinese). Hu Bei Min Zu Xue Yuan Xue Bao 2000;17:50.

69 Ma XL, Zhou FZ, Ma Y: A combination of medical and external counterpulsation therapy in patients with cerebral thrombosis (in Chinese). Xian Dai Lin Chuang Yi Xue Sheng Wu Gong Cheng Xue Za Zhi 2000;6:59-60.
70 Liu XD, Zhou CY: Management of ischemic stroke patients with defibrase plus external counterpulsation (in Chinese). He Nan Shi Yong Shen Jing Ji Bing Za Zhi 2001;4:59-60.

71 Zhang RH: External counterpulsation in treatment of ischemic stroke (in Chinese). Zhong Guo Kang Fu 2001;16:172-173.

72 Liu MX, Lu H, Liu XM, Zhang XL: Clinical benefits of external counterpulsation and early rehabilitation therapy in patients with ischemic stroke (in Chinese). Zhong Guo Wu Li Yi Xue Yu Kang Fu Za Zhi 2003;25:160161. 